\title{
Analytical meanders of selected systems for thermo-renovation of historical buildings
}

\author{
Barbara $\mathrm{Ksit}^{1, *}$, Mariusz Gaczek ${ }^{1}$ \\ ${ }^{1}$ Poznan University of Technology, Poland
}

\begin{abstract}
The article contains an analysis of selected systems for thermorenovation of vertical partitions in protected buildings. Historical buildings often require thermo-renovation, but in practice their "insulation" can be applied only internally on partitions without decorations. Internal thermorenovation methods can be classified according to heat exchange and moisture transport. For the purpose of this paper, the methods were analysed in terms of diffusion-open and diffusion-closed systems, and compared in a multi-variant aspect. The calculations were made assuming a wall with the moisture content up to $3 \%$, a wall with the very high moisture content up to $11 \%$, and for a wet wall with a constant inflow of water due to capillary action. They attempted to evaluate the effectiveness of various thermo-modernisation treatments in building partitions in the aspect of protection against permanent moisture growth, mould development and improvement of their overall heat protection, considering the 8-year time interval. Several different sets of materials were included in a multivariate analysis, as well as various scenarios of the possible effects of their use. The paper is summarised with conclusions regarding the effectiveness and risk related to the application of different internal methods of thermo-renovation of partitions.
\end{abstract}

\section{Introduction}

Modern methods of internal insulation of walls generally have to face two challenges: reduce the thermal transmittance $U$ (which is a relatively simple procedure) and prevent a constant increase in the moisture content in partitions.

The existing methods of wall insulation can be divided according to:

a) mode of action of thermal insulation:

- insulation with material that increases the thermal resistance of the partition,

- insulation with material that reflects the thermal radiation,

- insulation with material characterised by both of the effect,

b) influence on vapour diffusion through the partition:

- isolation not affecting the diffusion of water vapour through the partition - vapourpermeable insulation,

- isolation significantly affecting the diffusion of water vapour through the partition vapour barrier.

${ }^{*}$ Corresponding author: barbara.ksit@put.poznan.pl 


\section{Legal requirements}

\subsection{Worldwide}

The doctrinal document on the protection of monuments is the Venetian Card from 1964 - International Charter for the Conservation and Restoration of Monuments and Historic Places. The Venetian Card is a continuation of the Athens Charter passed in 1931.

\subsection{Poland}

The superior source of regulations in Poland, which constitute the protection of monuments, their care and renovation, is the Act of July 23, 2003 on the protection and care of historical monuments (Journal of Laws, No. 162, item 1568, as amended). All activities related to the conservation and protection of monuments must be performed in accordance with the provisions contained in this act.

In practice, this means that all works that we want to carry out in the building (including obtaining a decision on land development) depend on the positive opinion issued by a conservator-restorer. The legislator requires taking account of protective measures when preparing and updating the concepts of national spatial development plan, province development strategy or province spatial development plan (Art. 18.). Thus, already at the stage of planning, there are envisaged appropriate actions to preserve historical buildings and monuments in good condition. According to the 2015 list, almost 50\% of historical buildings require renovation [1]. A frequent problem found in historical building components is their destruction caused by moisture and freezing.

\section{The object under study}

The object of the study was a building erected during the interwar period and it was used to analyse selected internal thermo-renovation systems.

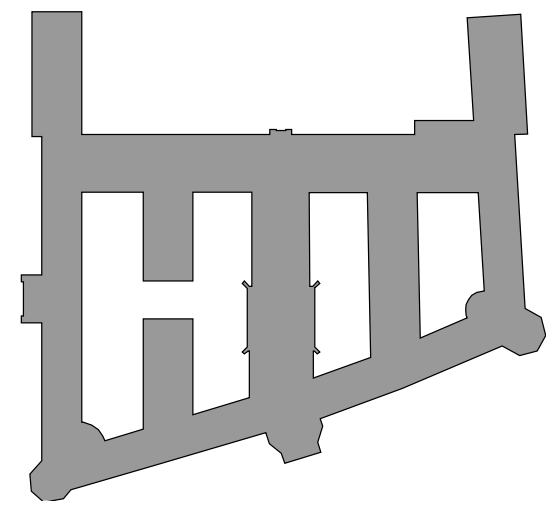

Fig. 1. Demonstrative floor plan of the building.

The building is a fragmented structure with a trapezoidal floor plan [Fig. 1]. It consists of three floors with pitched and flat roofs, perimeter wings have a lean-to roof with an attic from the street side [Fig.2]. Most of the ceilings were made as wooden structures. Walls were constructed of solid ceramic bricks in various dimensions. Macroscopic tests determined that in most cases the thickness of the walls oscillated between $57-67 \mathrm{~cm}$, max $78 \mathrm{~cm}$, and $\min 47 \mathrm{~cm}$ (thickness of the external wall in the current warehouse). The wall finish: exterior - lime-sand plaster approx. $2.5 \mathrm{~cm}$ thick, interior - cement and lime plaster 
approx. $2 \mathrm{~cm}$ thick, painted with dispersion paint, corridors - oil paint up to a height of $1.5 \mathrm{~m}$. Paint coat in a bad condition, locally dissipated due to the high moisture content in the external wall. However, during the local inspection, no mycological changes were found in the available part of the building. Exterior plaster above the plinth fragmentarily destroyed and disintegrated. The object is subject to conservation protection based on an entry in the register of monuments.

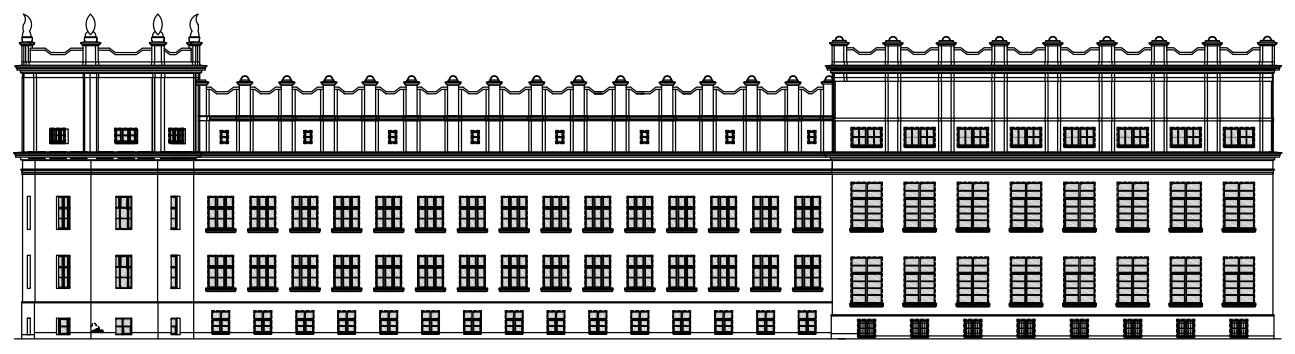

Fig. 2. Considered western facade of the building.

\subsection{Moisture content tests}

Moisture measurements were made with the drying and weighing method, and the moisture content map was produced using additional dielectric meters. On the basis of the analysis, it was established that the moisture content measured in November and December in 90 control points within the available part of the building ranged from $<3 \%$ (walls with permissible moisture content) to $11 \%$ (walls with high moisture content). In turn, on the basis of the analysis of the results of salinity content tests, the following levels of salts were determined:

- nitrates - low to medium,

- sulphates - low to medium,

- chlorides - low to medium.

Table 1. Exemplary results of tests [4].

\begin{tabular}{|c|c|c|c|c|c|}
\hline \multirow{2}{*}{ No. } & \multirow{2}{*}{ Date of test } & SO $^{\mathbf{4 2 -}}$ & $\mathbf{C l}^{-}$ & NO $^{\mathbf{3}}$ & Moisture content \\
\cline { 3 - 6 } & & {$[\%$ mass $]$} & {$[\%$ mass $]$} & {$[\%$ mass $]$} & {$[\%$ mass $]$} \\
\hline 1. & $2017-11-13$ & $0.78 \%$ & $0.00 \%$ & $0.00 \%$ & $2.52 \%$ \\
\hline 2 & $2017-11-13$ & $0.77 \%$ & $0.24 \%$ & $0.12 \%$ & $1.34 \%$ \\
\hline 3 & $2017-11-13$ & $0.38 \%$ & $0.00 \%$ & $0.00 \%$ & $8.34 \%$ \\
\hline 4 & $2017-11-13$ & $0.80 \%$ & $0.25 \%$ & $0.13 \%$ & $2.27 \%$ \\
\hline 5 & $2017-11-13$ & $0.20 \%$ & $0.00 \%$ & $0.00 \%$ & $3.00 \%$ \\
\hline 6 & $2017-11-13$ & $0.79 \%$ & $0.00 \%$ & $12.00 \%$ & $1.00 \%$ \\
\hline 7 & $2017-11-29$ & $0.20 \%$ & $0.00 \%$ & $0.00 \%$ & $3.34 \%$ \\
\hline 8 & $2017-11-29$ & $0.20 \%$ & $0.00 \%$ & $0.01 \%$ & $1.50 \%$ \\
\hline 9 & $2017-11-29$ & $0.20 \%$ & $0.00 \%$ & $0.25 \%$ & $1.89 \%$ \\
\hline
\end{tabular}

The samples for testing were taken at approx. $1 \mathrm{~m}$ above the ground floor that was approx. the level of the ground. The depth of sampling was about $10 \mathrm{~cm}$. 


\subsection{Selected internal thermo-renovation systems}

Engineering practice offers various methods of internal thermal insulation of walls depending on the water transport phenomena that may occur in building partitions [2, 3]. Suggested solutions must take into account both the specific characteristics of materials used for thermal insulation and/or vapour barriers, as well as the parameters of fastening elements and surface finish materials. Therefore, individual solutions should be complete systems or properly selected material sets.

The analysis included:

- system with thermal insulation material (PUR foam) between the vapour barriers (aluminium foil sheets) - system 1,

- system with thermal insulation material (PIR foam) between the vapour retarder (metallized kraft paper) from the wall side and the vapour barrier (aluminium foil) from the room side - system 2 ,

- system with capillary active and open to diffusion thermal insulation material (mineral plates) - system 3.

Table 2. Parameters with units of the selected systems [4].

\begin{tabular}{|c|c|c|c|}
\hline System & 1. & 2 & 3 \\
\hline Thermal insulation material & PUR foam & PIR foam & Mineral plate \\
\hline Bulk density & $40 \mathrm{~kg} / \mathrm{m}^{3}$ & $30 \mathrm{~kg} / \mathrm{m}^{3}$ & $85-110 \mathrm{~kg} / \mathrm{m}^{3}$ \\
\hline $\begin{array}{c}\text { Thickness of thermal insulation } \\
\text { material }\end{array}$ & $100 \mathrm{~mm}$ & $100 \mathrm{~mm}$ & $100 \mathrm{~mm}$ \\
\hline $\begin{array}{l}\text { Thermal transmittance of } \\
\text { thermal insulation material }\end{array}$ & $0.024 \mathrm{~W} /(\mathrm{m} \cdot \mathrm{K})$ & $0.022 \mathrm{~W} /(\mathrm{m} \cdot \mathrm{K})$ & $0.042 \mathrm{~W} /(\mathrm{m} \cdot \mathrm{K})$ \\
\hline Method of assembly & Metal stud framing & Metal stud framing & Mortar \\
\hline Mineral fine levelling & $\begin{array}{c}\text { Gypsum } \\
\text { finish/Plaster }\end{array}$ & $\begin{array}{c}\text { Gypsum } \\
\text { plasterboard }\end{array}$ & $\begin{array}{c}\text { Gypsum } \\
\text { finish/Plaster }\end{array}$ \\
\hline $\begin{array}{c}\text { Thickness of mineral fine } \\
\text { levelling }\end{array}$ & $7 \mathrm{~mm}$ & $12,5 \mathrm{~mm}$ & $7 \mathrm{~mm}$ \\
\hline Vapour barrier & $\begin{array}{l}\text { Aluminium foil on } \\
\text { both sides of } \\
\text { thermal insulation }\end{array}$ & $\begin{array}{l}\text { Metallized kraft } \\
\text { paper and } \\
\text { aluminium foil }\end{array}$ & None \\
\hline $\begin{array}{l}\text { Water vapour diffusion } \\
\text { resistance - core }\end{array}$ & 50 & 50 & $3 / 7$ \\
\hline $\begin{array}{l}\text { Water vapour diffusion } \\
\text { resistance factor - total }\end{array}$ & $>32,000$ & $>17,000$ & No data \\
\hline Reaction to fire - core & $\mathrm{E}$ & $\mathrm{F}$ & A1 \\
\hline Reaction to fire - total & No data & $\mathrm{B}-\mathrm{s} 1, \mathrm{~d} 0$ & No data \\
\hline
\end{tabular}

\section{The analysis of selected internal thermo-renovation systems}

\subsection{Boundary conditions - the partition before thermal insulation}

All calculations were made with WUFI PRO 6.1 that was used to analyse non-stationary processes of heat and moisture flow through building partitions. External climate parameters were assumed for Warsaw. Internal climate parameters were assumed on the basis of ISO 13788 (i.e. PN-EN ISO 13788) for rooms with humidity class 3 (relative humidity at an internal temperature of $20^{\circ} \mathrm{C}$ : $50-60 \%$ ). The analyses included the exterior 
wall from the west side, as the most exposed to driving rain. The construction of partitions after thermal insulation was adopted in accordance with thermal insulation manufacturers' guidelines. The comprehensive analyses included partitions with the moisture content $3 \%$, whereas the initial analyses also took into consideration partitions with the moisture content $11 \%$.

For individual wall layers in the dry state it was assumed:

- exterior plaster

- thermal conductivity $\lambda=0.58 \mathrm{~W} /(\mathrm{m} \cdot \mathrm{K})$,

- water vapour diffusion resistance factor $\mu=7$,

- solid ceramic brick wall (bulk density $1800 \mathrm{~kg} / \mathrm{m}^{3}$ )

- thermal conductivity $\lambda=0.60 \mathrm{~W} /(\mathrm{m} \cdot \mathrm{K})$,

- water vapour diffusion resistance factor $\mu=15$,

- interior plaster

- thermal conductivity $\lambda=0.80 \mathrm{~W} /(\mathrm{m} \cdot \mathrm{K})$

- water vapour diffusion resistance factor $\mu=19$,

- paint coating with diffusion resistance $S_{\mathrm{d}}=0.05 \mathrm{~m}$.

As a result of calculations, the following values of water content were determined for the wall $47 \mathrm{~cm}$ thick, moisture content $3 \%$ :

- water content in exterior plaster $14.2 \mathrm{~kg} / \mathrm{m}^{3}$,

- water content in brick wall $54.0 \mathrm{~kg} / \mathrm{m}^{3}$,

- water content in interior plaster $85.3 \mathrm{~kg} / \mathrm{m}^{3}$,

- deep source of moisture (causing the persistence of moisture content) $\quad 93650 \mathrm{~g} /\left(\mathrm{a} \cdot \mathrm{m}^{2}\right)$.

As a result of calculations, the following values of water content were determined for the wall $63 \mathrm{~cm}$ thick, moisture content $3 \%$ :

- water content in exterior plaster $13.0 \mathrm{~kg} / \mathrm{m}^{3}$,

- water content in brick wall $54.0 \mathrm{~kg} / \mathrm{m}^{3}$,

- water content in interior plaster $83.7 \mathrm{~kg} / \mathrm{m}^{3}$,

- deep source of moisture (causing the persistence of moisture content) $\quad 84290 \mathrm{~g} /\left(\mathrm{a} \cdot \mathrm{m}^{2}\right)$.

For the purpose of comparison, annual fluctuations in water content values were determined for the dry wall, without a deep source of moisture. As a result of calculations, assuming a sufficiently long wall drying time, there were obtained the maximum values of water content:

- wall $47 \mathrm{~cm}$ up to $10 \mathrm{~m}-0.28-0.36 \%$,

- wall $63 \mathrm{~cm}$ up to $10 \mathrm{~m}-0.27-0.36 \%$,

- wall $47 \mathrm{~cm}$ at $10-20 \mathrm{~m}-0.55-1.58 \%$,

- wall $63 \mathrm{~cm}$ at $10-20 \mathrm{~m}-0.61-1.51 \%$.

The ranges of water content were determined by taking different values of free water saturation $\left(250-330 \mathrm{~kg} / \mathrm{m}^{3}\right)$ and water absorption coefficient $\left(6,0-16,2 \mathrm{~kg} /\left(\mathrm{m}^{2} \cdot \mathrm{h}^{0,5}\right)\right)$ of exterior plaster. Increase in the values of saturation or/and water absorption coefficient reduces the water content in the wall.

\subsection{Assumptions regarding the calculation of the minimum temperature coefficient on the internal surface}

On the basis of the regulation on technical conditions for buildings and their location, the required critical value of $f_{\mathrm{Rsi}}$ - the temperature coefficient in rooms heated to a temperature of at least $20^{\circ} \mathrm{C}$ in residential, collective residence and public utility buildings - should be determined on the assumption that the value of average monthly relative humidity of internal air is equal $\varphi=50 \%$. Adjusting to this requirement, the values of temperature coefficient on the internal surface were calculated for the city of the object's location. 


\subsection{Construction - the partition after thermal insulation}

The following specifications were taken for the construction of the partitions after thermorenovation:

- $\operatorname{system}(1)$ :

- existing exterior plaster $0.025 \mathrm{~m}$,

- solid ceramic brick 0.47 and $0.67 \mathrm{~m}$,

- interior plaster $0.025 \mathrm{~m}$,

- air layer $0.025 \mathrm{~m}$,

- vapour barrier - aluminium foil $0.05 \mathrm{~mm}$,

- PUR foam $0.1 \mathrm{~m}$,

- vapour barrier - aluminium foil $0.05 \mathrm{~mm}$,

- top layer based on organic resin $\mathrm{Sd}=1 \mathrm{~m}$.

- system (2):

- existing exterior plaster $0.025 \mathrm{~m}$,

- solid ceramic brick 0.47 and $0.67 \mathrm{~m}$,

- interior plaster $0.025 \mathrm{~m}$,

- air layer $0.025 \mathrm{~m}$,

- vapour retarder - metallized paper $\mathrm{Sd}=100 \mathrm{~m}$,

- PIR foam $0.1 \mathrm{~m}$,

- vapour barrier - aluminium foil,

- gypsum plasterboard.

- system (3):

- existing exterior plaster $0.025 \mathrm{~m}$,

- solid ceramic brick 0,47 and 0,67 m,

- interior plaster $0.025 \mathrm{~m}$,

- mineral adhesive mortar $0.01 \mathrm{~m}$,

- thermo insulation mineral plate $0.1 \mathrm{~m}$,

- mineral adhesive mortar $0.01 \mathrm{~m}$,

- mineral fine levelling,

- silicate paint.

\subsection{Change in the moisture content in the wall layers from 1 October 2018 to 1 October 2026 after internal thermal insulation}

Assuming the same deep source of water as in the case of the partition before thermal insulation, after applying system 1 (PUR foam core), the moisture content in the wall increased to max. $6.31 \%$. As of October 1, this gives an increase from $2.87 \%$ to $4.74 \%$. There was also a slight increase in the moisture content in the insulation foam, from $1.79 \mathrm{~kg} / \mathrm{m}^{3}$ to $1.90 \mathrm{~kg} / \mathrm{m}^{3}$. After applying system 2 (PIR foam core), the moisture content in the wall increased to max. $6.36 \%$. As of October 1 , this gives an increase from $2.87 \%$ to $4.75 \%$. There was also a slight increase in the moisture content in the insulation foam, from $1.79 \mathrm{~kg} / \mathrm{m}^{3}$ to $2.14 \mathrm{~kg} / \mathrm{m}^{3}$. Increase in the water content in the analysed PUR and PIR foams up to $10 \mathrm{~kg} / \mathrm{m}^{3}$ has virtually no effect on reducing the thermal insulation properties of these materials. After applying system 3 (mineral plate), the moisture content in the wall increased to max. 5.51\%. As of October 1, this gives an increase from $2.87 \%$ to $4.11 \%$. There was also an increase in the moisture content in the thermal insulation plate, from $8.1 \mathrm{~kg} / \mathrm{m}^{3}$ to $31.73 \mathrm{~kg} / \mathrm{m}^{3}$ (max. $36.88 \mathrm{~kg} / \mathrm{m}^{3}$ ), without any tendency for its further 
development. The results given relate to the wall $47 \mathrm{~cm}$ thick and up to $10 \mathrm{~m}$ high. The results for the wall $63 \mathrm{~cm}$ thick are similar. All the considered solutions meet the requirement for $f_{\text {Rsi }}$ value for the prevention of building damage as a result of mould formation $f_{\mathrm{Rsi}}>f_{\mathrm{Rsi} \text { max }}[6]$, as shown in the Table 3.

In order to compare the behaviour of thermal insulation materials, the analysis also considered the lack of an additional source of water in the wall. Change in the moisture content in the analysed thermal insulation foams was almost identical to that of the wet wall to a constant value. When considering the mineral plate, a slight decrease in the water content was found - to $8.07 \mathrm{~kg} / \mathrm{m}^{3}$ as of October 1 (max. water content during the year $14.74 \mathrm{~kg} / \mathrm{m}^{3}$ ). In the case of system 3 , with the mineral insulation plate, the authors also investigated how the parameters of mortar for fixing plates and making external coatings affected the hygrothermal behaviour of the insulated wall. It was found that in the case of a gradually drying wall, without an additional deep source of water, the influence of mortar parameters was insignificant (negligibly small). However, it turned out to be important when an additional source of water in the wall was considered. In any situation, an increase in the water content in the mineral insulation plate reduced the water content in the wall. In the case of a gradually drying wall, changes in the water content in the materials, depending on the parameters of mortar, were relatively low e.g. wall - from 10.01 to $10.16 \mathrm{~kg} / \mathrm{m}^{3}$, insulation plate - from 8.26 to $\left.8.07 \mathrm{~kg} / \mathrm{m}^{3}\right)$. In the case of the wet wall, changes in the water content were higher (e.g. wall - from 71.71 to $73.93 \mathrm{~kg} / \mathrm{m}^{3}$, insulation plate - from 36.10 to $\left.31.73 \mathrm{~kg} / \mathrm{m}^{3}\right)$, what affected the value of thermal transmittance (increase from 0.523 to $0.566 \mathrm{~W} /\left(\mathrm{m}^{2} \cdot \mathrm{K}\right)$ ).

\subsection{Thermal transmittance values after thermal insulation}

Considering the losses due to thermal transmittance, the parameters of external walls during the heating season are of significant importance, e.g. from the beginning of October to the end of April. For these months are determined thermal transmittance values $U$. They are given in WUFI as the transient $U$-value.

For the thickness of thermal insulation plates adopted in all systems as $100 \mathrm{~mm}$, the following values of thermal transmittance were obtained:

System 1 - wall $47 \mathrm{~cm}$, initial moisture content $3 \%$ :

- maximum value in the previous year (month: March) $U=0.241 \mathrm{~W} /\left(\mathrm{m}^{2} \mathrm{~K}\right)$.

System 1 - wall $63 \mathrm{~cm}$, initial moisture content $3 \%$ :

- maximum value in the previous year (month: March) $U=0.245 \mathrm{~W} /\left(\mathrm{m}^{2} \cdot \mathrm{K}\right)$.

System 2 - wall $47 \mathrm{~cm}$, initial moisture content $3 \%$ :

- maximum value in the previous year (month: March) $U=0.226 \mathrm{~W} /\left(\mathrm{m}^{2} \cdot \mathrm{K}\right)$.

System 2 - wall $63 \mathrm{~cm}$, initial moisture content 3\%:

- maximum value in the previous year (month: March) $U=0.231 \mathrm{~W} /\left(\mathrm{m}^{2} \cdot \mathrm{K}\right.$ ).

System 3 - wall $47 \mathrm{~cm}$, initial moisture content $3 \%$ :

- maximum value in the previous year (month April) $U=0.524 \mathrm{~W} /\left(\mathrm{m}^{2} \cdot \mathrm{K}\right)$.

In the absence of a constant inflow of water to the wall:

- maximum value in the previous year (month: April) $U=0.357 \mathrm{~W} /\left(\mathrm{m}^{2} \cdot \mathrm{K}\right.$ ).

The average values of thermal transmittance from the previous year during the 8-year period in question and the values of temperature coefficient for the analysed systems are given in Table 3 . 
Table 3. Temperature coefficients for external walls insulated with thermal insulation plates $100 \mathrm{~mm}[4]$.

\begin{tabular}{|l|c|c|c|}
\hline \multicolumn{1}{|c|}{ Partition } & $\begin{array}{c}\boldsymbol{U} \\
{\left[\mathrm{W} /\left(\mathrm{m}^{2} \cdot \mathrm{K}\right)\right]}\end{array}$ & $\boldsymbol{f} \boldsymbol{R s i}$ & $\boldsymbol{f}$ Rsi,max \\
\hline Wall 47 cm; moisture content 3\%; thermal insulation - system 1 & 0.210 & 0.948 & 0.729 \\
\hline Wall 63 cm; moisture content 3\%; thermal insulation - system 1 & 0.205 & 0.950 & 0.729 \\
\hline Wall 47 cm; moisture content 3\%; thermal insulation - system 2 & 0.196 & 0.950 & 0.729 \\
\hline Wall 63 cm; moisture content 3\%; thermal insulation - system 2 & 0.192 & 0.953 & 0.729 \\
\hline Wall 47 cm; moisture content 3\%; thermal insulation - system 3 & 0.461 & 0.885 & 0.729 \\
\hline
\end{tabular}

\subsection{Moisture conditions on the existing wall surface after thermal insulation}

As expected, the hygrothermal conditions of existing walls deteriorated as a result of thermal insulation. In addition to the shown increase in the water content, wall materials underwent significant temperature changes. The internal surfaces under thermal insulation were very moist, as is illustrated in Figures 3-5. (horizontal axis 8-yers; vertical axis temperature $-\max 25^{\circ} \mathrm{C}$ and relative humidity values $-\max 100 \%$ )

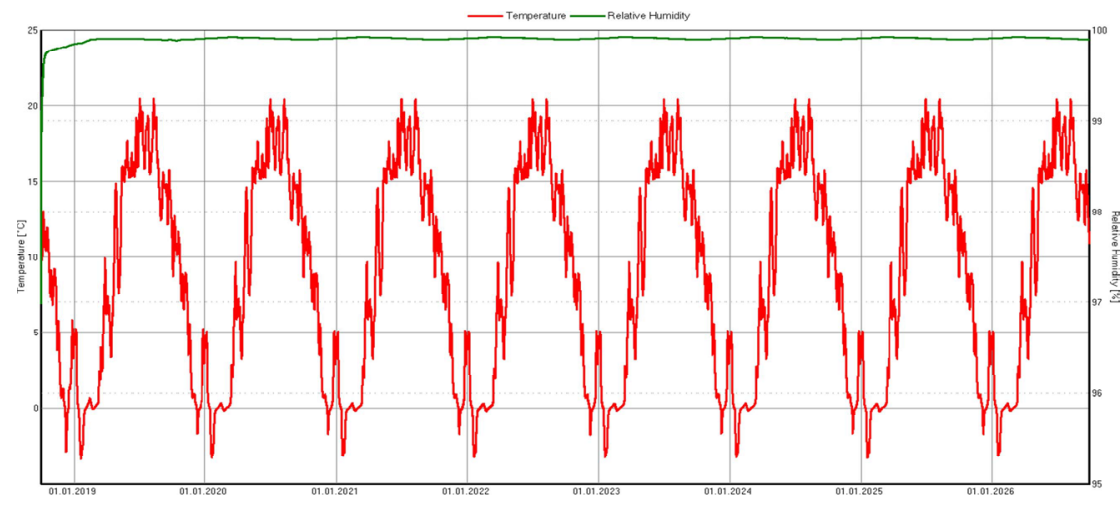

Fig. 3. Change in the temperature (red)and relative humidity values (green) on the surface of the existing plaster after insulating the wall $47 \mathrm{~cm}$ thick with the use of system 1 [4].

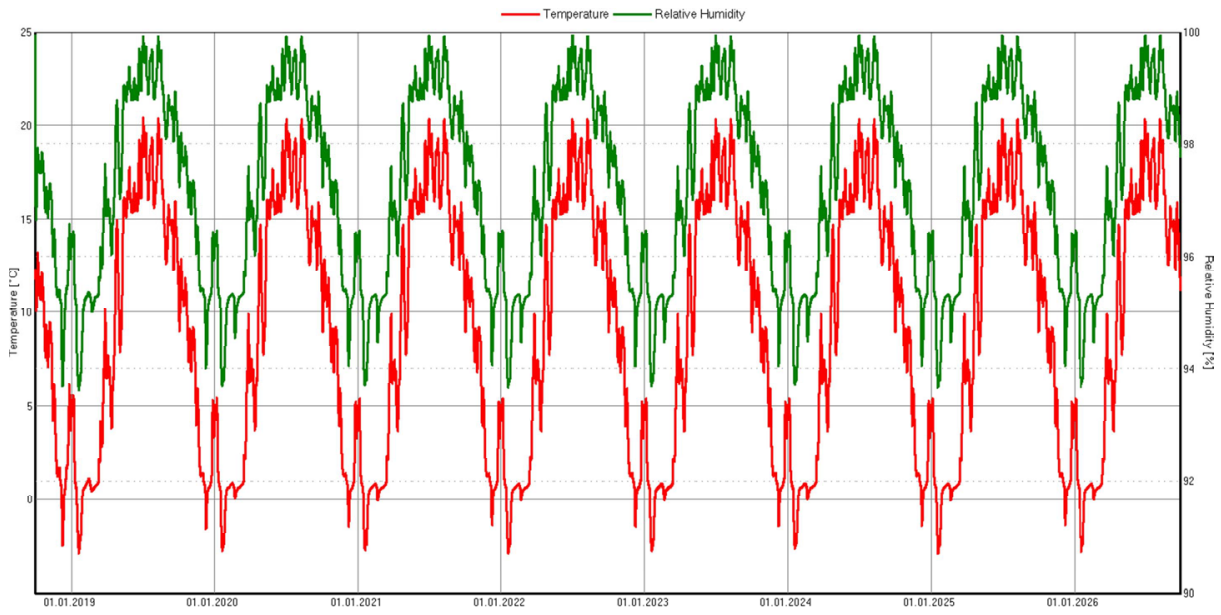

Fig. 4. Change in the temperature(red) and relative humidity values(green) on the surface of the metallized paper (aluminium layer on the side of PIR foam) after insulating the wall $47 \mathrm{~cm}$ thick with the use of system 2 [4]. 


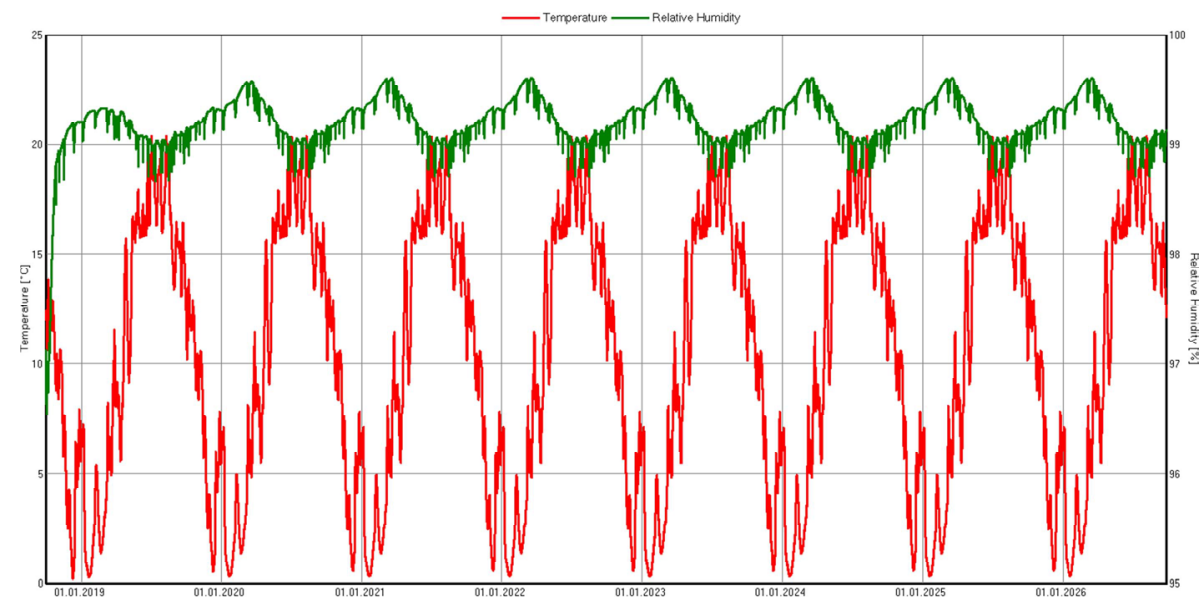

Fig. 5. Change in the temperature(red) and relative humidity values (green)on the surface of the existing plaster after insulting the wall $47 \mathrm{~cm}$ thick with the use of system 3 [4].

\section{Summary}

Vertical partitions in historical buildings are very often contaminated with salts and characterise with high moisture content. In the analysed object, the maximum moisture content was approx. $11 \%$, but for the majority of tested parts of walls, the number did not exceed 3\%, which is the average value referring to the moisture content in walls. Due to the destruction of construction materials, their possible biodegradation, unfavourable impact on the indoor climate, deterioration of thermal insulation and external appearance of walls, it was assumed that in the partitions with the moisture content significantly higher than average, the value should be permanently reduced before the installation of thermal insulation. Therefore, in the analyses carried out, the authors focused on walls with the moisture content $3 \%$.

The calculations showed the influence of various thermal insulation solutions and material parameters on the change in the water content in particular layers of the wall and its thermal transmittance. Vapour barrier solutions give a significant improvement in U-value, but they cause the largest increase in the moisture content in the wall. The use of mineral plates causes a slightly smaller increase in the moisture content in the wall (by less than $1 \%$ ), but the value of thermal transmittance is more than twice as high, with the same thickness of thermal insulation $(100 \mathrm{~mm})$. Increasing the thickness of the mineral plate results in the improvement of $U$ - value, but at the same time the water content increases both in the wall and in the plate.

When considering the assembly of systems, it is worth noting that the fastening of insulation plates to the metal stud framing creates an unventilated layer of air, which allows for mould growth on adjacent surfaces. In the case of walls with very low moisture content, it is important to prevent, during installation and operation, the creation of empty space for water vapour penetration, if the insulation is to function as a diffusion barrier. An important parameter is also the external layer of the wall, because it is noticeable that above $10 \mathrm{~m}$ the humidity values significantly change as a result of cutting rain.

Due to the age and technical conditions of historical buildings, it is necessary to carry out a thorough analysis before planning internal thermo-renovation in order to choose an optimal method of insulation improvement. The modelling of processes, with the use of dedicated computer software, facilitates analysing but also requires extensive engineering expertise. It is important to properly recognize existing construction and finish materials 
and select appropriate parameters of components forming thermal insulation systems. Unfortunately, manufacturers often do not provide all necessary data regarding building materials. This may result in uncertainty of the obtained results or time-consuming analysing, in order to consider the impact of many possible material parameters.

It is difficult to predict how much increased moisture in walls in combination with a change in temperature distribution in their thickness will affect possible frost damage, biodegradation and deterioration of internal living conditions. The periodic technical verification of insulated walls and indoor climate parameters is recommended in order to react in time and to prevent the biodegradation of building partitions. It also helps to expand knowledge on practical research, since each inside-wall implementation requires an individual approach to thermo-renovation methodology.

\section{References}

1. M. Kwiecień, (Analiza metod renowacji zabytkowych konstrukcji murowanych, Master's thesis, Supervisor: Ph.D. B. Ksit. Poznan University of Technology, 2013)

2. R. Wójcik, (Docieplania budynków od wewnątrz. Medium, Warsaw, 2017)

3. D. Zirkelbach, (Innendämmung - Worauf ist zu achten? Fraunhoferinstitut für Bauphysik IBP, Holzkirchen https://wufi.de/de/literatur/, (2011)

4. B. Ksit, M. Gaczek: (Opinia naukowo-techniczna dotyczaca porównania systemów docieplania wykonywanych od wewnatrz. Poznan University of Technology, Institute of Structural, 2018)

5. D. Zirkelbach, A. Binder, H. M. Künzel, (Kapillaraktive Innendämmungen - Wirkung und Beurteilung, 1. Internationaler Innendämmkongress, Technische Universität Dresden, 2011)

6. Regulation of the Minister of Infrastructure and Construction as of 14 November 2017 changing the regulation on technical conditions for buildings and their location, Journal of Laws 2017, item 2285 (2017) 